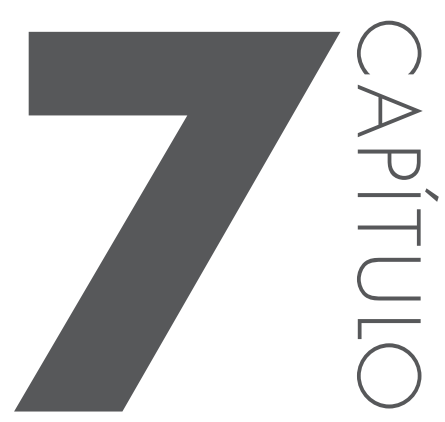

\title{
POLÍTICA DE GERENCIAMENTO DE RESÍDUOS SÓLIDOS RECICLÁVEIS EM TUPACIGUARA (MG)
}

Soares de Moura, Valquíria ${ }^{1 *}$; Mendes Ferreira, Idelvone ${ }^{2}$

I Universidade Federal de Goiás Mestranda do Programa de Pós-Graduação em

Geografia - RC/UFG Núcleo de Estudos e Pesquisas Socioambientais - NEPSA-CNPq/ UFG

2 Universidade Federal de Goiás (UFG) Professor do Programa de Pós-Graduação em Geografia - RC/UFG Núcleo de Estudos e Pesquisas Socioambientais - NEPSA-CNPq/ UFG

* email: valquiriamoura.ufg@gmail.com

\section{RESUMO}

Visando solucionar a questão do lixo, tem-se que os programas de coleta seletiva podem ser considerados como uma das possíveis soluções, visto que preconiza a reutilização de diversos materiais como papéis, vidros, plásticos e metais, entre outros. Nesse contexto, o município de Tupaciguara, localizado na mesorregião do Triângulo Mineiro, conta com a implantação de um Programa de Coleta Seletiva, gerido pela Prefeitura Municipal, com gestão e logística da Secretaria Municipal de Meio Ambiente, o qual visa estruturar a coleta, separação e a destinação dos resíduos sólidos para a reciclagem, bem como promover a inclusão socioprodutiva dos catadores através de uma 
Associação dos Catadores de Material Reciclável de Tupaciguara - ASCAMAT e Cooperativa de Reciclagem. Neste sentido, o principal objetivo deste trabalho pauta-se em analisar o funcionamento do Programa de Coleta Seletiva realizado em Tupaciguara (MG) por meio da Associação de Catadores. A metodologia empregada é a elaboração de referencial teórico como suporte às análises a serem realizadas; a prática de trabalhos de campo na sede da Associação e Cooperativa e população humana do Município para conhecimento da realidade das mesmas, bem como a busca de informações na Prefeitura Municipal de Tupaciguara e demais Órgãos Públicos vinculados ao Programa, necessários ao desenvolvimento da pesquisa.

Palavras-chave: Coleta Seletiva de Lixo. Município de Tupaciguara (MG). Reciclagem. 


\section{INTRODUC̣ÃO}

O surgimento dos descartáveis, tanto de origem orgânica quanto inorgânica, associados ao modelo de autoconsumo da sociedade consumista, vem ocasionando um aumento excessivo do lixo, que na linguagem técnica significa sinônimo de resíduos sob estado sólido ou semilíquido, produzido pelo homem. $\mathrm{O}$ que fazer com a grande quantidade de resíduos produzidos diariamente se tornou um dos problemas mais discutidos entre a população humana e ambientalistas na atualidade, pois sua geração cresce de maneira equivalente ao aumento do consumo.

Em função disso, com o intuito de preservar o ambiente e melhorar a qualidade de vida das populações envolvidas, o Poder Público e a sociedade humana organizada, buscam alternativas práticas para tentar resolver esse dilema. Como exemplo é possível citar os programas de coleta seletiva e reciclagem, os quais vêm sendo considerados uma das possíveis soluções de tratamento ou redução dos resíduos sólidos, visto que esta prática possibilita reutilizar materiais como papéis, vidros, plásticos, metais, entre uma diversidade de outros tipos de bens recicláveis.

A reciclagem tem sido a ação que desperta maior interesse por parte da população humana, pois além de possibilitar benefícios ambientais como a economia de matérias-primas não renováveis, economia de energia nos processos produtivos e aumento da vida útil dos aterros sanitários, ela estimula o desenvolvimento de uma maior consciência ambiental por parte dos indivíduos que do processo participa, instigando assim os Órgãos Públicos a adotar também Programas de Educação Ambiental, uma base fundamental para a sustentabilidade dessas ações.

Diante do exposto, a cidade de Tupaciguara (MG) não se torna uma exceção, pois a cada ano que passa sua taxa de urbanização, considerando o período desde sua formação urbanística, cresce de forma significativa. Isso acontece, principalmente nos últimos anos, devido à instalação do Distrito Industrial na Cidade contendo importantes empreendimentos econômicos tais como a Vegas Plastic, Tuplast, Briqfeno, Axis Aerospace dentre outros, especialmente no setor agroindustrial; nos setores de educação; bem como de prestações de serviços que, consequentemente acabam favorecendo a vinda de migrantes de diferentes partes do país, resultando assim no aumento da geração de resíduos sólidos urbanos, aos quais devem ser descartados e depositados em lugares apropriados.

Considerando o fato de que o Programa de Coleta Seletiva em Tupaciguara (MG) trata-se de um projeto recente, visto que foi criado no ano de 2013 e 
executado apenas a partir do ano de 2014,é possível que não haja muitos estudos aprofundados e suficientes a cerca do tema e sobre as condições ambientais referentes à Cidade, desta forma é que se deu a intenção de contribuir com o mesma procurando entender a satisfação da população humana atendida pelo Programa.

A Cidade pesquisada foi escolhida não só pela afinidade devido minha origem e residência em sua área urbana, mas por observar de perto o comportamento dos moradores quanto à educação e cuidados ambientais, suas necessidades e, principalmente, o posicionamento do Poder Público no que diz respeito aos problemas referentes à qualidade de vida da população humana, obediência aos requisitos legais normativos e condicionantes dos órgãos ambientais. Vale ressaltar que a importância deste projeto justifica-se por uma problemática inserida em um contexto nacional, não apenas local ou regional, que é o adequado gerenciamento dos resíduos sólidos, mais especificamente os recicláveis, por parte dos programas de coleta seletiva como contribuição ao ambiente e sociedades dele dependentes.

Portanto, o presente trabalho busca compreender, por meio de pesquisa teórica, documental e de campo, a dinâmica de funcionamento do Programa de Coleta Seletiva e Reciclagem na cidade de Tupaciguara (MG) desde sua implantação no ano de 2013, a partir de sua gestão e logística que competem à Secretaria de Meio Ambiente em conjunto com a Associação dos Catadores de Material Reciclável de Tupaciguara (ASCAMAT).

\section{CARACTERÍSTICAS E LOCALIZAC̣ÃO DA ÁREA DA PESQUISA}

O município de Tupaciguara (MG) situa-se ao norte do Triangulo Mineiro e também pertence à Mesorregião do Alto Paranaíba, conforme pode ser visualizado na Figura 1, no Estado de Minas Gerais.

De acordo com dados do Instituto Brasileiro de Geografia e Estatística (IBGE, 2010), o Município abrange uma área de $1.824 \mathrm{~km}^{2}$ e possui uma população humana, estimada até o ano de 2010, de 24.188 habitantes, dos quais 22.042 residem na área urbana e 2.146 na zona rural.

Conforme dados históricos do IBGE (2010), a região onde se encontra o atual Município de Tupaciguara era habitada primitivamente pelos índios Caiapós e foi atravessada em 1722 pela Bandeira de Bartolomeu Bueno da Silva - o Anhanguera. Para proteger-se dos ataques dos aborígines, Anhanguera edificou dezoito aldeiamentos em sua rota, alojando nelas índios de varias 
tribos, principalmente Bororos, oriundos de Mato Grosso. Desbravada assim a região, dando início a colonização, com a divisão das terras em Sesmarias.

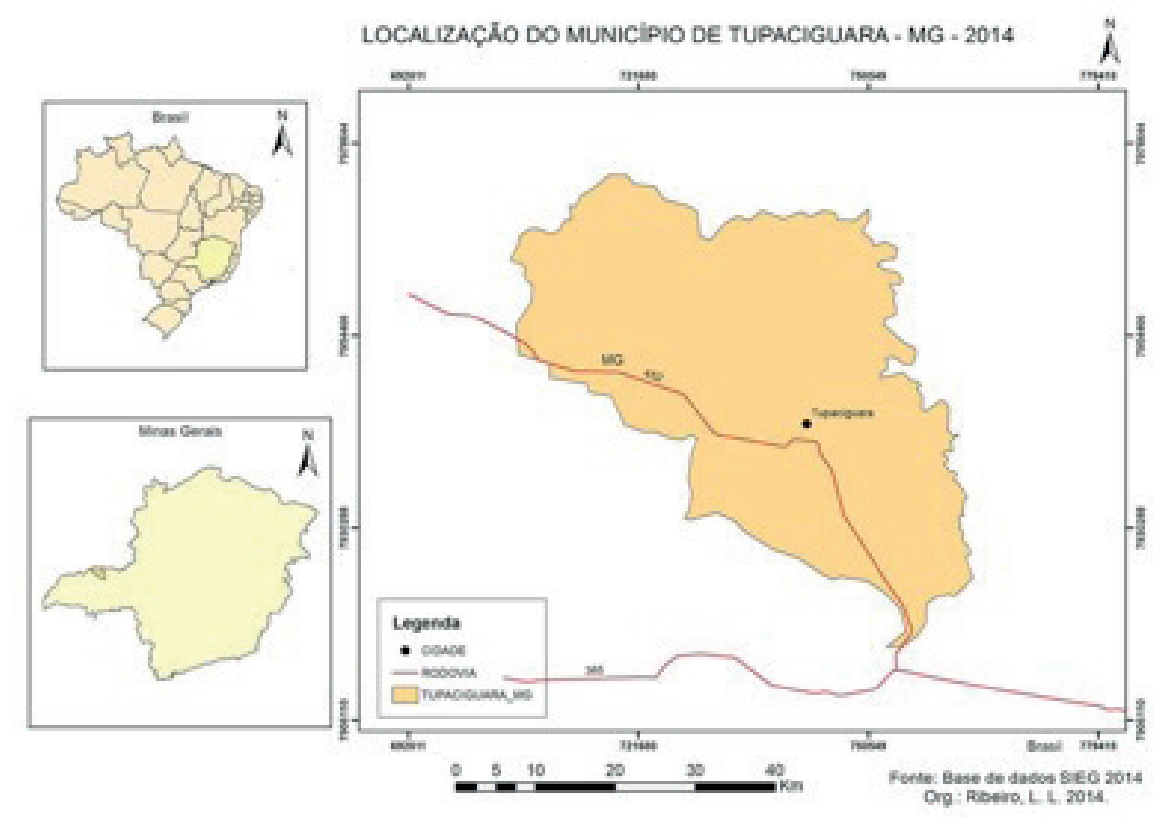

Figura 1- Localização geográfica do município de upaciguara (MG) - 2014.

Organização técnica: MOURA, V. S. de. (2014). Organização Cartográfica: RIBEIRO, L. L. (2014).

De 1841 a 1842, graças aos esforços de D. Maria Teixeira, devota de Nossa Senhora da Abadia, foi construída uma pequena capela no local, então pertencente a Paróquia de Monte Alegre, por esse motivo, a povoação que se formava em torno da Capela passou a ser chamada de "Abadia do Monte Alegre" ou "Abadia do Bom Sucesso", adotando posteriormente o topônimo de origem indígena Tupaciguara, a qual significa "Terra da Mãe de Deus" (IBGE, 2010).

Segundo Canuto e Vlach (2004), na década de 1920 o lugarejo deu um impulso em seu desenvolvimento. Até a metade do século XX, a economia do Município baseou-se na criação de gado e no cultivo do arroz, visto que estas atividades não implicavam em grandes investimentos e não necessitavam de muita mão de obra. Sendo então, os principais produtos, aqueles advindos da agricultura e pecuária, tais como embalagens de agrotóxicos, ração animal, resíduos de plantações, dentre outros.

Ao contrário das atividades rurais, as industriais e as atividades de serviços diversificaram-se pouco devido a vários fatores, dentre os quais, a baixa 
densidade demográfica da cidade, a falta de mão-de-obra qualificada e o fato de a atividade mais importante para a economia do Município continuar sendo a agropecuária.

O município de Tupaciguara produz, em grande escala, soja e leite. Observase também que o rendimento da cana-de-açúcar e tomate é significativo, visto que atualmente encontra-se no Município uma grande Usina de cana-de-açúcar denominada Aroeira, a qual se tornou um fator dominante na economia do Município e favoreceu o aumento populacional humano com a chegada de migrantes de diversas partes.

\section{GESTÃO DOS RESÍDUOS SÓLIDOS: ALGUMAS DISCUSSÕES A CONSIDERAR.}

De acordo com Santos (2007), o desenvolvimento para o conforto e o bem-estar humano, produzidos a partir da Revolução Industrial, levou à intensificação do material descartável, ocasionando um aumento da quantidade de resíduos gerados e não utilizados pelo homem. Muitos destes provocam a contaminação do meio ambiente e ocasionam riscos à saúde humana, principalmente nas áreas urbanas que não levaram em consideração a necessidade de adequação, e de locais específicos, para depósito e tratamento dos resíduos sólidos.

O Instituto Brasileiro de Geografia e Estatística (IBGE, 2008) por meio da Pesquisa Nacional de Saneamento Básico (PNSB) divulgou que 99,96\% dos municípios brasileiros têm serviços de manejo de Resíduos Sólidos, mas $50,75 \%$ deles dispõem seus resíduos em vazadouros; $22,54 \%$ em aterros controlados e $27,68 \%$ em aterros sanitários. Estes dados apontaram que $3,79 \%$ dos municípios têm unidade de compostagem de resíduos orgânicos; $11,56 \%$ têm unidade de triagem de resíduos recicláveis e $0,61 \%$ têm unidade de tratamento por incineração.

Essa prática do descarte inadequado têm provocado sérios danos à saúde pública e ao ambiente, associando-se ao triste quadro socioambiental de um grande número de famílias que, excluídas socialmente, sobrevivem dos "lixões" de onde retiram o sustendo a partir da comercialização dos materiais recicláveis.

De acordo com o Manual de Gerenciamento de Resíduos (2006), os aterros sanitários são a única estrutura que atende completamente a legislação, pois se trata de uma obra de engenharia que possui sistema de impermeabilização inferior, captação e tratamento do chorume (líquido poluente gerado pela decomposição do lixo), gestão adequada dos resíduos e, além disso, possui menores gastos com a implantação, operação e encerramento dos mesmos. De 
acordo com Santos (2007) o aterro sanitário de resíduos sólidos:

Consiste na técnica de disposição de resíduos sólidos urbanos no solo, sem causar danos ou riscos à saúde pública e à segurança, minimizando os impactos ambientais, método este que utiliza os princípios de engenharia para confinar os resíduos sólidos ao menor volume permissível, cobrindo-os com uma camada de terra na conclusão de cada jornada de trabalho ou a intervalos menores se for necessário (SANTOS, 2007, p. 5).

Conforme Santos (2007, p. 18) , a Organização Mundial da Saúde - OMS definiu o lixo como “[...] qualquer material que seu proprietário não deseja mais e que não possui valor comercial”. Essa citação reflete um pensamento incorreto e desatualizado sobre o lixo pois, atualmente resíduo é tratado como sinônimo de matéria-prima, conforme pode-se verificar no Manual de Gerenciamento Integrado de Resíduos Sólidos (2008) desenvolvido pelo Instituto Brasileiro de Administração Municipal - IBAM:

Há de se destacar, no entanto, a relatividade da característica inservível do lixo, pois aquilo que já não apresenta nenhuma serventia para quem o descarta, para outro pode se tornar matériaprima para um novo produto ou processo. Nesse sentido, a ideia do reaproveitamento do lixo é um convite à reflexão do próprio conceito clássico de resíduos sólidos. É como se o lixo pudesse ser conceituado como tal somente quando da inexistência de mais alguém para reivindicar uma nova utilização dos elementos então descartados (IBAM, 2008, p. 25).

Nesse sentido, Gomes (1989) aponta que os resíduos sólidos são classificados de acordo com seus diferentes graus de biodegrabilidade, tais como: facilmente degradáveis - materiais de origem biogênica; moderadamente degradáveis papel, papelão e outros produtos celulósicos; dificilmente degradáveis - trapos, couro (tratado), borracha e madeira; não degradáveis - vidros, metal e plásticos.

De acordo com o Manual de Gerenciamento de Resíduos (2006) desenvolver e implantar um Plano de Gerenciamento de Resíduos (PGR) é fundamental para qualquer órgão que deseja maximizar as oportunidades e reduzir custos e riscos associados à gestão de resíduos sólidos.

Os mesmos preceitos da implantação de qualquer sistema de gestão devem ser aplicados no caso de um PGR, o qual deve assegurar que todos os 
resíduos serão gerenciados de forma apropriada e segura, desde a geração até a destinação final. Isso significa adotar os passos apresentados na Figura 2.

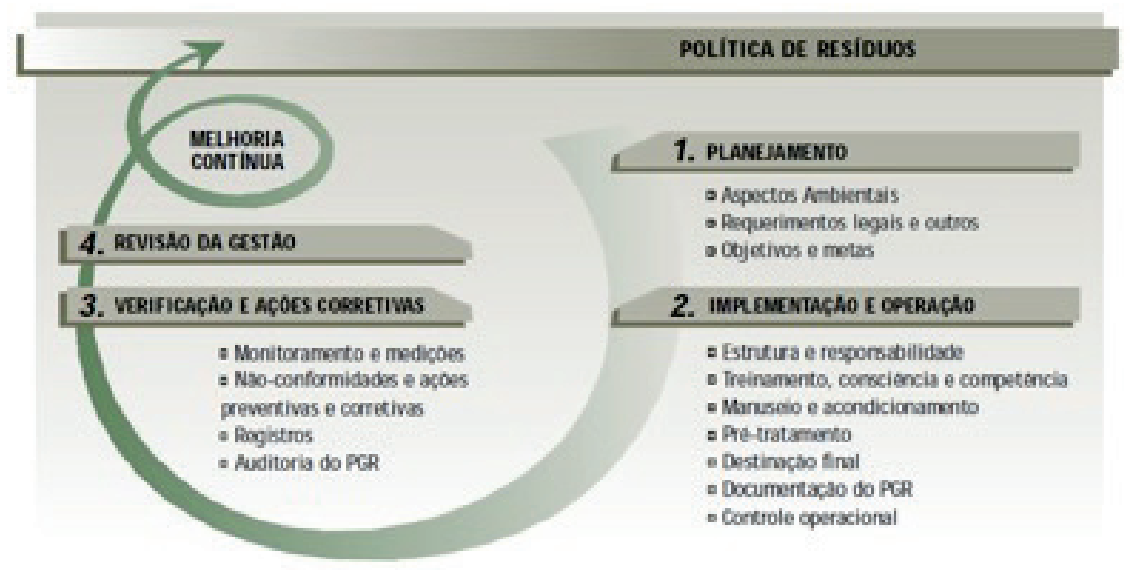

Figura 2- Passos para uma política de resíduos.

Fonte: Manual de Gerenciamento de Resíduos/Biblioteca SEBRAE (2006).

Nesse contexto, Maroun (2006) apresenta as definições dos “3Rs”, na ordem em que os mesmos devem ser considerados:

- Redução da geração na fonte: implantação de procedimentos que priorizam a não geração dos resíduos. Estas ações podem variar da implantação de novas rotinas operacionais a alterações tecnológicas no processo produtivo.

- Reutilização de resíduos: neste caso, o resíduo é reaproveitado sem que haja modificação na sua estrutura. Um exemplo é a utilização dos dois lados de uma folha de papel.

- Reciclagem de resíduos: no caso da reciclagem, há um beneficiamento no resíduo para que o mesmo seja utilizado em outro (ou até no mesmo) processo. Como exemplo nota-se na reciclagem de latinhas de alumínio, as quais, passam por um processo de beneficiamento, para que o alumínio seja reaproveitado no processo (MAROUN, 2006, p. 13).

Alguns dos grandes desafios deste milênio referem-se ao que fazer e qual a destinação da enorme quantidade de resíduos produzidos, visto que o aumento da produção de lixo ocorre de forma ameaçadora, sendo considerado algo a ser superado no que tange a degradação do ambiente. Nesse sentido, o poder 
público e a própria população humana buscam possíveis soluções, como a criação de programas de coleta seletiva e reciclagem.

Santos (2007) considera que o termo "reciclagem" designa o processo de transformação dos materiais recicláveis em outros produtos, por intervenção da ação industrial. Para isso, a coleta seletiva e inclusive o processo da Educação Ambiental é de fundamental importância para que a reciclagem, a reutilização e a própria compostagem (separação pós-coleta) possam ser efetuadas.

A coleta seletiva consiste na separação dos materiais recicláveis (denominados secos, como papéis, plásticos, metais, vidros, etc.) da matéria orgânica (denominados úmidos, como sobras de alimentos, frutas, legumes, etc.) nas próprias fontes geradoras: residências, escolas, escritórios e outros estabelecimentos. Esta prática facilita a reciclagem porque os materiais estarão limpos e, consequentemente, com maior potencial de reaproveitamento (SANTOS, 2007, p. 26).

Nesse sentido, Santos (2007) define que para implantar um processo de coleta seletiva ou coleta diferenciada faz-se necessário levar a população humana a tomar consciência de que o material reciclável não é propriamente lixo, devendo, portanto, ser acondicionado de forma segregada; promover e oferecer condições para que essa população possa descartar seletivamente papéis, plásticos, vidros e metais, instalando recipientes identificados nas praças e estabelecimentos públicos e efetuando a coleta com regularidade; implantar um centro de triagem para separação, classificação e armazenamento destes materiais até a sua reutilização e/ou comercialização; promover estudo de mercado para conhecer a viabilidade de comercialização dos materiais recicláveis; prever o recolhimento dos resíduos orgânicos, os quais poderão ser aproveitados para gerar energia, gás ou adubo orgânico.

Adamns (2006) conclui que para compreender o processo da reciclagem é importante "reciclar" o conceito de lixo, deixando de enxergá-lo como algo sujo e inútil em sua totalidade, passando a perceber que o lixo é fonte de riqueza. Esta é uma ação simples e de grande valor para os catadores de lixo, o ambiente e as futuras gerações.

De acordo com a União Brasileira para a Qualidade - UBQ (2004), numa apuração de dados realizada pela Associação Brasileira do Alumínio (ABAL), em conjunto com a Associação Brasileira dos Fabricantes de Latas de Alta Reciclabilidade (ABRALATAS), foi possível verificar que o Brasil recicla menos de $5 \%$ de seus resíduos, sendo que esse percentual é de 40\% nos EUA e na Europa. 
Apesar de o Brasil não estar na lista dos países mais preocupados com o desperdício, a UBQ (2004) ainda considera que o Brasil é campeão na reciclagem de papelão e de latas de alumínio, pois reciclou $89 \%$ de todas as latas de alumínio vendidas em 2003, e no caso do papelão a reciclagem foi de $72 \%$, enquanto que na Europa esse percentual foi de $65 \%$, deixando a desejar no que diz respeito à reciclagem de outros materiais, como exemplo, cita-se os $21 \%$ de plástico e os $38 \%$ de vidro e de papel. Ainda assim, o Brasil destacase como líder mundial em reciclagem de latas de alumínio, pelo terceiro ano consecutivo, considerando as nações onde esta atividade não é obrigatória por Lei.

A reciclagem proporciona inúmeros benefícios às sociedades, à economia e ao ambiente. Como exemplo, é possível citar as garrafas plásticas de refrigerantes transformadas em tecido para fazer calça jeans; as toneladas de plásticos reciclados que contribuem com a economia de petróleo, e que depois de reciclados ainda podem virar carpetes, mangueiras, cordas, entre outros produtos do gênero; e ainda, uma tonelada de papeis reciclados que poupam 22 árvores, consomem $71 \%$ a menos de energia elétrica deixando de poluir o ar em $74 \%$ ao fabricá-lo, assim como diversos tipos de papéis podem ser reciclados sete vezes ou mais (ADAMNS, 2006, p. 02).

Alguns programas de coleta seletiva e reciclagem já implantados por cooperativas de outras cidades e que estão dando certo, podem servir de exemplo, como é o caso da cidade de Curitiba (PR). De acordo com Susin (2007), foi a primeira cidade a implantar o Sistema de Coleta de Lixo Seletivo no Brasil, no ano de 1989 . Hoje o programa atinge $100 \%$ da Cidade, que tem uma produção de 2,2 toneladas de lixo seco por dia. $\mathrm{O}$ autor ainda revela que desse total, 550 toneladas são separadas, equivalente a $70 \%$ da população humana que contribui com a coleta seletiva. O lixo reciclável é coletado em todos os bairros da Capital Paranaense e diariamente enchem 42 caminhões, mas essa quantia não representa a totalidade do material que é separado nas casas, comércio e empresas, pois na Cidade existem muitos catadores de lixo reciclável e através de acordo com lojas e condomínios coletam o material. Além da coleta seletiva, a Capital Paranaense faz uma coleta específica para lixo tóxico domiciliar, como pilhas, baterias e remédios. O lixo comum é destinado ao aterro sanitário, que também recebe os resíduos de mais 14 municípios da Região Metropolitana.

De acordo com Garcia (2011), Caxias do Sul (RS) se tornou cidade modelo para todo Brasil no que diz respeito à reciclagem de lixo, pois, produz cerca de 410 toneladas diárias de lixo doméstico, esse volume é recolhido pela Companhia de Desenvolvimento de Caxias do Sul - CODECA, de segunda a 
sábado levando os resíduos para os Aterros Sanitários e para Associações de Reciclagem. O trabalho envolve 260 funcionários com 29 caminhões, sendo 4 para a coleta mecanizada de resíduos orgânicos, 18 para a coleta manual de orgânicos e 7 para resíduos seletivos. Os próprios moradores da Cidade se propuseram a manter uma o espaço urbano mais limpo, separando e levando todo lixo doméstico até os contêineres de reciclagem que ficam espalhados estrategicamente por toda Cidade.

Em Porto Alegre (RS) a coleta é feita em circuitos percorridos por 18 caminhões, no sistema também porta a porta, que coletam semanalmente os materiais previamente separados pela população humana. Cada bairro é atendido uma vez por semana e a renda média mensal dos catadores que trabalham nas usinas varia de 2 a 3 salários mínimos (RIBEIRO; LIMA, 2000).

Em Belo Horizonte (MG), a coleta seletiva, iniciada em 1993, faz parte do Programa de Manejo Diferenciado de Resíduos Sólidos, que engloba os recicláveis, a matéria orgânica gerada pelo setor de alimentação e as atividades de poda e capina, e o reaproveitamento do entulho da construção civil. O êxito do Programa de Belo Horizonte pode ser atribuído à distribuição descentralizada das atividades e sua estrutura integrada, com a articulação entre as diversas instâncias municipais, coordenadas por um Comitê Gestor (GRIMBERG; BLAUTH, 1998, p. 78).

Conforme Moura (2012), em Ituiutaba o Programa de Coleta Seletiva foi implantado no ano de 2000 e em 2003, passou a operar em sistema cooperativista sendo assim denominado, Cooperativa de Reciclagem de Ituiutaba - COOPERCICLA. Atualmente a coleta seletiva atende toda a Cidade, mas devido ao aumento da demanda, os novos bairros não são atendidos completamente. Inicialmente a COOPERCICLA contava com 22 cooperados, já em 2011 contava com 39 cooperados diretos e para o recolhimento dos materiais recicláveis, alugam da Prefeitura Municipal três caminhões que percorrem a Cidade de segunda a sexta-feira fazendo a coleta diariamente.

É importante ressaltar ainda quanto à importância da Cooperativa para a Cidade no que diz respeito à inclusão social, pois no início da coleta seletiva a Superintendência de Água e Esgotos (SAE) fez um trabalho de seleção, juntamente com assistentes sociais, o qual contemplou inicialmente pessoas que trabalhavam no antigo lixão da Cidade, assistindo catadores que atuavam nas ruas, albergados, alcoólatras, dependentes químicos e portadores de necessidades especiais, sem oportunidades do mercado formal de trabalho (MOURA, 2012, p. 35).

Em Uberlândia (MG), de acordo com dados apresentados pela Prefeitura Municipal (2014), foi implantada em 2011 a coleta seletiva bairro a bairro, e 
quase dois anos após o lançamento desta iniciativa, 15 bairros integrados foram beneficiados. Isso representa uma abrangência de mais de $35 \%$ da população humana de Uberlândia. Antes do programa se efetivar em uma nova região, a Secretaria Municipal de Serviços Urbanos realiza visitas de casa em casa para explicar o funcionamento aos moradores. Nos dias específicos para cada bairro, os ecocaminhões, ao passar pelas vias, emitem um sinal sonoro para lembrar que é dia de coleta. Em 2012, a média de recolhimentos de resíduos foi de 160 toneladas por mês, são materiais que deixam de ser jogados no Aterro Sanitário e foram encaminhados para associações e cooperativas de catadores e recicladores. Neste quesito, Uberlândia também se inclui num índice ainda pequeno, mas de destaque no cenário nacional. De acordo com o Instituto Brasileiro de Geografia e Estatística (IBGE, 2012), apenas 14,8\% das cidades no Brasil com Coleta Seletiva tem parceria com as associações cooperativas.

Além da economia gerada pela reciclagem, a coleta seletiva colabora com a preservação do ambiente, ao diminuir a quantidade de lixo que chega aos aterros sanitários, minimizando os impactos causados pelos resíduos sólidos.

Dessa maneira, muitas pessoas são beneficiadas com a coleta seletiva e reciclagem, principalmente os catadores, pois apesar de terem um papel muito importante em todo esse processo, alguns deles ainda reconhecem a sua contribuição ambiental, buscando além do salário/remuneração a sua inclusão social.

\section{RESULTADOS ESPERADOS}

As considerações finais deve ser uma das ultimas etapas apresentada pelo pesquisador, para que o leitor possa compreender o que foi trabalhado no decorrer da pesquisa, possibilitando uma visão clara e objetiva do assunto abordado, segundo uma metodologia proposta. É o momento da pesquisa em que são expostos e discutidos os resultados relevantes alcançados pelo pesquisador.

Como o trabalho encontra-se em andamento, até o presente momento, os resultados alcançados dizem respeito ao levantamento bibliográfico e visitas iniciais a campo para percepção da realidade local e suas influencias no contexto dos indivíduos envolvidos no processo. Nessa etapa, percebe-se que o Programa de Coleta Seletiva implantado esta em fase de adaptações, visto que são menos de dois anos de funcionamento, visto que é um processo lento de assimilação pelos moradores da Cidade.

Para tanto, está sendo averiguados variáveis que se farão importantes no 
decorrer da pesquisa no que diz respeito ao gerenciamento da Cooperativa de Reciclagem e Associação de Catadores de materiais recicláveis de Tupaciguara (MG); se existe programas de Educação Ambiental eficiente como base fundamental da relação socioambiental sendo aplicados; análise e discussão do Programa de Coleta Seletiva e Reciclagem; satisfação e conhecimento das pessoas atendidas quanto ao Programa.

Assim, espera-se que a pesquisa em curso possa contribuir de forma significativa para a cidade de Tupaciguara (MG) e seus moradores, em detrimento de possíveis melhorias em seu Programa de Coleta Seletiva que venham a ser pontuadas no desenvolvimento da mesma em beneficio da evolução positiva socioambiental. Essa é nossa meta maior. 


\section{Title: Policy Management of Solid Waste Recycling in Tupaciguara (MG) Since the Year 2010}

\section{Abstract}

The selective collection programs are considered as a possible solution to the garbage problem, since advocates the reuse of various materials such as paper, glass, plastics and metals, among others. The municipality of Tupaciguara, located in the middle region of Triangulo Mineiro, includes the implementation of a Selective Collection Program, managed by the City, with management and logistics Municipal Secretariat of Environment, which aims to facilitate the collection, separation and disposal of solid waste for recycling, and promote socio-productive inclusion of waste pickers organized into an Association of Collectors of Recyclable Material Tupaciguara - ASCAMAT and Cooperative recycling. In this sense, the main objective of this work is guided in analyzing the operation of the Selective Collection Program held in Tupaciguara (MG) through its Association of Collectors convening the same. The methodology employed is the elaboration of theoretical framework to support the analysis to be performed; the practice of fieldwork at the Cooperative Association and thirst for knowledge of the reality of these as well as seeking information on Tupaciguara Municipal Government and other public bodies linked to the Program needed to develop the survey. As the work is in progress, to date, the results relate to the literature survey and initial visits to the field for perception of local realities and their influences in the context of the individuals involved.

Keywords: Waste Recycling. Municipality of Tupaciguara (MG). Recycling. 


\section{REFERÊNCIAS}

ADAMNS, B. G. Reciclando Conceitos. In: Revista Educação Ambiental em Aç̃ão, 2006. Disponível em: < http:// www.revistaea.org/artigo.php?idartigo=463\&dlass=05>. Acesso em: 25 dez. 2012.

ALVES-MAZZOTII, A. J.; GEWANDSZNAJDER, F. 0 planejamento de pesquisas qualitativas. In: 0 método nas ciências naturais e sociais: pesquisa quantitativa e qualitativa. 2. ed. São Paulo: Pioneira Thomson Learning, 2002. p. 147-176.

ASSOCIACTÃO BRASILEIRA DE LATAS. Reciclagem de latas de alumínio. Disponível em: <http://www.abralatas. org.br/>. Acesso em: 28 dez. 2012.

ASSOCIACCAO BRASILEIRA DE NORMAS TÉCNICAS. NBR 8.419: Apresentação de Projetos de Aterros Sanitários de Resíduos Sólidos Urbanos: procedimentos. Rio de Janeiro, 1985. 9 p.

CANUTO, A. F. A.; VLACH, V. R. F. Poder local e territorialidades na cidade de Tupaciguara (MG): uma introdução. In: VI Congresso Brasileiro de Geógrafos - Setenta anos da AGB: as transformações do espaç, e a Geografia no século XXI, 2004, Goiânia (GO). VI Congresso Brasileiro de Geógrafos, 2004. CD-ROM.

GARCIA, M. Caxias do Sul: cidade modelo em reciclagem de lixo. Revisado em fev. 2011. Disponível em: <http:// www.giramundos.com/site/?p=1546>. Acesso em : 26 nov. 2012.

GOMES, L. P. Estudo da caracterização física e da biodegradabilidade dos resíduos sólidos urbanos em aterros sanitários. 1989. 178 f. Dissertação (Mestrado em Hidráulica e Saneamento) - Escola de Engenharia de São Carlos, Universidade de São Paulo, São Paulo, 1989.

GRIMBERG, E.; BLAUTH, P. Coleta seletiva: recidando materiais, reciclando valores. São Paulo: POLLS, 1998. $103 \mathrm{p}$.

INSTITUTO BRASILEIRO DE ADMINISTRAÇÃO MUNICIPAL. Manual de Gerenciamento Integrado de Resíduos Sólidos. Rio de Janeiro: IBAM/ SEDU, 2008.

INSTITUTO BRASILEIRO DE GEOGRAFIA E ESTATISTICA. Estatística Populacional Municipal 2010. Rio de Janeiro: IBGE, 2012. Disponível em: <http://www.bge.gov.br/cidadesat/topwindow.htm?1 >. Acesso em: 20 nov. 2012. INSTITUTO BRASILEIRO DE GEOGRAFIA E ESTATISTIICA. Estatística Populacional Municipal 2010. Tupaciguara: IBGE, 2014 Disponível em: <http://cidades.ibge.gov.br/ painel/historico.php?lang=\&codmun=317020\&search=mi nas-gerais|tupaciguara|infograficos:historico >. Acesso em: 22 de setembro de 2014.

LUNA, S. V. Planejamento de pesquisa: uma introduccão. São Paulo: EDUC, 2005. 108 p. (Série Trilhas).

MAROUN, C. A. Manual de Gerenciamento de Resíduos: guia de procedimentos passo a passo. 2 ed. Rio de Janeiro: GMA, 2006.

MOURA, V. S. O Programa de Coleta Seletiva em Ituiutaba (MG). In: Revista Eletrônica Boletim de Geografia, Maringá , v.30, n. 3, p. 41 - 53, Ago./ Set. 2012.

RIBEIRO, T. F; LIMA, S. C. Coleta Seletiva de Lixo Domiciliar - Estudo de Caos. Caminhos de Geografia - Revista Online. Programa de Pós-Graduação em Geografia. Uberlândia, p. 50-69, dez. 2000. Disponível em: <http://www. seer.ufu.br/index.php/caminhosdegeografia/ article/viewFile/10067/5938>. Acesso em: 26 nov. 2012.

SANTOS, F. C. A Logística Reversa de Resíduos Sólidos em Ituiutaba: do diagnóstico à elaboração de um modelo pró-ativo. 2007. 184f. Dissertação (Programa de Pós-graduação em Geografia) - Instituto de Geografia, Universidade Federal de Uberlândia, Uberlândia, 2007. Disponivel em: <http://www.ig.ufu.br/sites/ig.ufu.br/files/ 
Anexos/Bookpage/Anexos_FlavioCosta.pdfs Acesso em: 25 nov. 2012.

ASSOCIACÃO DOS MUNICÍPIOS DA MICROREGIÃO DO VALE DO PARANÁ́BA. Dados sobre coleta seletiva de Tupaciguara, 2014. Disponível em: <http://www.amvapmg.org.br/l/tupaciguara-se-prepara-para-implantarcoleta-seletiva-do-lixo/> Acesso em: 20 de setembro de 2014.

SUSIN, R.; PIRES, F. Primeira Cidade Brasileira com Coleta Seletiva de Lixo. Revisão out. 2007. Disponível em: <http://www.rankbrasil.com.br/Recordes/Materias/OLvs /Primeira_Cidade_Brasileira_Com Coleta_Seletiva_ De_Lixo>. Acesso em: 16 dez. 2012.

UNIÃO BRASILEIRA DE QUALIDADE. Dados sobre reciclagem, 2004. Disponível em: <http://www.setorreciclagem. com.br/modules.php?name=News\&file=article\&sid=28>. Acesso em 25 nov. 2012. 